\title{
Translation Principles of English Loan Words
}

\author{
WANG Xiao-yan, XU Tan \\ Changchun University, Changchun, China
}

\begin{abstract}
With the intensifying of globalization and blending of different cultures, more and more foreign words, especially English words, are becoming Chinese transliteration words. During this process, those words must be introduced according to Chinese people's cognitive habit and thinking mode. The present paper, with many latest popular Chinese transliteration words as example, explores three kinds of translation principle of those English loan words: (1) translating according to Chinese language habit, (2) transliteration and paraphrase, and (3) creating new words. And more importance is attached to the first one, which covers: avoiding choosing Chinese characters at random; avoiding using uncommon words and avoid arousing derogatory association. The paper believes that even though some of the loan words are translated according to their sound, the correspondent Chinese characters should be well chosen.
\end{abstract}

Keywords: loan words, translation principles, transliteration

\section{Introduction}

With the development of human civilization, changes keep taking place in society and our daily life and new concepts, ideas, and new things emerge continuously. Man has come to know more and more about the world around. All this is reflected in language. So "language is just like a mirror, refecting everything that exists in human society" (W. Y. ZHANG, 1999, p. 153). As new things emarges continously, and if there were no equivalent words in one language, we have to borrow the new words from other languages. "Words taken over from foreign languages are known as borrowed words or loan words or borrowings in simple terms" (W. Y. ZHANG, 1999, p. 19). English is a heavy borrower and has adopted words from all other major languages of the word. It is estimated that English borrowings constitude 80\% of the modern English vocabulary. So is Chinese, which has never ceased the absorbing of words in other languages since its existence almost 4,000 years ago. The main channel to turn those borrowings into Chinese is by translating. Generally speaking, there are two important ways to translate those foreign words into Chinese. One is to translate them according to the meaning and the other is to translate according to the sound. The later ones are known as transliteration words. Those borrowings have developed under the Chinese system of pronounciation, semantic, and meaning. During these processes, the words must be borrowed according to Chinese people's cognitive habit and thinking mode. Gradually they are well assimilated into the Chinese language. The present paper will briefly discuss the translation principles of some English loan words.

WANG Xiao-yan, associate professor, master, School of Foreign Languages, Changchun University.

XU Tan, assistant researcher, master, Scientific Research Administritive Department, Changchun University. 


\section{Translating According to Chinese Language Habits}

When the loan words become Chinese, they must be introduced according to Chinese people's cognitive habit and thinking mode. The development and changes of loan words are restricted to the inner patterns of a language system. At first loan words from English to Chinese must follow the characters of Chinese pronounciation and rules of Chinese word-formation, because Chinese character is the combination of pronounciation, form, and meaning. We can translate them according to the sound, but the Chinese characters are not chosen at random, they must be chosen according to Chinese thinking mode. Even though there are equivalents in Chinese we sometimes have to take cultural differences and features of Chinese language into consideration, especially the transliteration words.

\section{Avoiding Choosing the Chinese Characters at Randam}

Chinese belongs to an ideographic writing system, so looking at the characters themseves, you can guess the meaning of the words (L. WANG, 1993, p. 14). In translating an English loan word, the Chinese characters must be well-chosen. For example, “clone” is transliterated into “克隆” in Chinese, but in Hangkong and Taiwan, “复 制”, “转殖”, or “群殖” are sometimes also used. Yet “克隆” is accepted as the best translation, because in Chinese “隆” means “expansion”, which is in accordance with its original meaning: replica, twins, bouble; duplicate and copy. If it is transliterated as “克龙”, it cannot remind Chinese people’s right association. For another example, “lion” can be transliterated as “师子” and “Mary” as “马力”, but the category is not clear. So “狮子” and “玛丽” are the acceptable translation, in which “狮” indicates animal, while “丽”, which means “pretty and beautiful”, is a word specially for girl's name in Chinese.

Each characters in some of the transliteration words in Chinese themseves cannot only tell the readers the associate meaning of the original words but also tell a dramatic story behind the words. For instance, "Utopia” is “乌托邦” in Chinese, in which “乌” means “nothing”, “托” means “rely on” and “邦” means “a place or a country”, so together the three Chinese characters mean "There is no such beautiful places that you can rely on”. Now the word can refer to any hopes and plans that cannot be realized. “Gestapo” is transliterated as “盖世太保” in Chinese, which gives you a picture or an imagination describing a gang of hooligans or bodyguard who are doing something illegal openly. This transliteration word is both vivid and dramatic. For the same reason, “shampoo” can be transliterated into “香波” in Chinese. These two Chinese characters are also well-chosen words, in which “香” means “fragrant, pleasant smell”, while “波” means “waves”. The two characters have the association of “the waterfall-like hair with fragrant and pleasant smell”. “Bungee” is transliterated into “蹦极” in Chinese. The two Chinese characters are not chosen at random too, in which “蹦” means “jump”, and “极” means "extreme limitation". This translation reserves the original meaning of the English word and meanwhile remains the same pronounciation. For the same reason, "hacker, gene, talk show, and bandage” are transliterated as “黑客, 基因, 脱口秀, and 绷带”, in which “黑客” reminds people of “a dishonest visitor”, “基因” means “the basic unit of heredity”, “脱口秀” gives the association of “an excellent speaker with extraordinary talent in talking”, while “绷带” means “tight belt or strap”.

These Chinese transliteration words are formed in accordance with Chinese word-formation rules and they not only reserve the English pronouciation and meaning, but also sound like Chinese and accepted by Chinese and become Chinese transliteration words. 


\section{Avoiding Using Uncommen Words}

When we translate foreign things or concepts into Chinese, we should avoid using uncommen Chinese characters. For example, “Olympic” is “奥林匹克” in Chinese. The four Chinese characters are not only simple, but also pleasant to ears and give people a fine association. If it is transliterated into “嗷麟皮壳”, the charming of this word is gone completely. Since the two very uncommen Chinese characters “嗷麟” have no any correlation between each other, and the “皮壳” give people the funny association of “crust, shell, or hull”. So “奥林匹克” is an exerlant example of transliteration word. For another example, “Suez” is transliterated into “苏伊士” but not “苏彝士”, because “彝” is not a commen word in Chinese.

\section{Avoiding Arousing Derogatory Association}

When the transliteration word is not in accordance with Chinese thinking mode or the translation reminds people of wrong and derogatory association, it cannot be accepted and cannot become Chinese transliteration word. For example, “massage” cannot be transliterated as “马杀鸡”, which means “The horse killed the chicken”. Instead it is translated as “按摩” according to its function and meaning. "Congo”, a country in Africa, cannot be transliterated into “干果”, because it means “dry fruit” in Chinese, so “刚果” is the right transliteration word.

\section{Transliteration and Paraphrase}

This method refers to using both transliteration and paraphrase at the same time, or using half transliteration and half paraphrase, so that readers can easily understand the meaning of the words at first glance. For example, “beer” can be transliterate into “皮”, “比”, “啤”, but they are hard to memorize and people would be confused about its meaning. Now “啤酒” is the correct translation. “啤” is translated according to the pronounciation, and “酒” is added according to its function. For the same reason, “swallowtail, jeep, ping-pang, and Big Ben, etc.” are not only transliterated as “燕尾, 吉普, 乒兵, 大本”, but “燕尾服, 吉普车, 乒乓球, 大本钟”. The category words “服, 车, 球, 钟” are added, so that their functions are clear.

“Miniskirt” can be translatered as “迷你裙” or “超短裙”, but “迷你裙” is more popular and vivid, in which “迷你” is tranliterated from “Mini”, while “裙” is translated from “skirt”. For the same reason, there are “迷你 店” (minishop), “迷你屋” (minihouse), “迷你玩具” (minitoy), “迷你景观” (miniature landscape) in Chinese now. “Mickey Mouse”, the most popular cartoon character, is translated as “米奇老鼠”, the nickname is “米老 鼠”, in which “米” is the transliteration of “Mickey”. The remarkable part of this translation is that “米”, which means "rice” in Chinese, is closely connected with “老鼠”, the "mouse”.

“Cambridge”, “Uncle Sam”, “motorcycle”, “salad oil”, and "X-ray”, etc., which are half translated and half paraphrased as “剑桥”, “山姆大叔”, “摩托车”, “色拉油”, “爱克斯光”, are other good examples of the same method.

\section{Creating New Words According to the Meaning}

As we all know, Chinese and English have great difference in phonological system, homophonic characters, and word. Therefore, it is impossible to make the pronounciation of the transliteration Chinese loan words completely identical with the original English words. But we can creat a new word to solve the problem. Creating new words is the meaning-based translation of loan words, in which the original meanings of the English words have no close connection with the Chinese transliteration words, while a new word is created according to the 
meaning (P. J. ZHANG, 2000, p. 179). For instance, “Coca-Cola” is translated into “可口可乐” in Chinese. But we all know that "Coca” is a South American bush, while "Cola”, which originated from "Kola”, is the products of the tree. In order to have the commercial effect, the inventer turned "Kola” into "Cola” and put a hyhpen between "Coca” and "Cola”, so "Coca-cola” is established. But the four Chinese characters have a special extrodinary meaning. “可口” can mean “tasty, palatable, delicious, etc.”, and “可乐” can mean “pleasant, happy, cool, etc.”. So together the Chinese transliteration of this words gives people the impression that "After drinking Coca-Cola, you will feel happy and cool”. What a nice thing it is! This translation can be regarded as the terrific example of transliteration words, or to be exact, the best translation of commercial advertisement. For the same reason, those famous drinks_- “Pepsi-cola”, “Mountain Dew”, “7-up”, “Mirinda”, and "Sprite” are translated into “百事可乐”, “百事激浪”, “七喜”, and “雪碧”. These words are created partly according to the meaning and partly according to the pronounciation of the original English words.

\section{Conclusion}

With the intensifying of globalization and blending of different cultures, Chinese will keep absorbing other cultures and words. And various principles need applying to translate them. The present paper only makes a rough exploration about some of those principles. Yet no matter what methods are used, when words are first taken over from English, they have to be influenced by linguistic factors and non-linguistic factors (WU, 1994, p. 94). The linguistic factors here refer to Chinese language habits. We all know that Chinese is famous for its ideographic writing system, so the characters of those transliteration words have to be well chosen, so that those translitertion words cannot only reserve the meaning of the original English, but also have the similiar pronouciation and even a more dramatic meaning. Those transliteration words enrich Chinese language. No-linguistic factors refer to the Chinese thinking modes and cultures. Chinese characters and culture are profound enough to translate the English loan words into proper Chinese and see to it that people can accept them and even love them. The translationg of loan words is the process of fusing different cultures, and also the typical example of globalization.

\section{References}

HE, Y. (2011). A study of the development trend and features in translating English loan words in modern Chinese. Journal of Ningbo Radio and TV University, (4), 49-51.

HU, Z. L. (2006). Linguistics a course book. Beijing: Beijing University Press.

WANG, L. (1993). History of Chinese vocabulary. Beijing: Commercial Press.

WANG, Z. K. (2002). A collegiate course in Chinese-English translation. Jinan: Shangdong University Press.

WU, L. Q. (1994). The study of the characteristics in Chinese transliteration words. Journal of Fudan University, (3), 82.

XIAO, M. Q. (2013). A tranlation study of English loan wrods. Education Teaching Forom, (44), 169-172.

YANG, X. P. (2007). A study of Chinese loan words. Shanghai: Shanghai People’s Publishing House.

ZANG, H. (2011). A brief comment on English loan words. Overseas English, (15), 14-15.

ZHANG, P. J. (2000). A course in English to Chinese translation. Shanghai: Shanghai Foreign Language Education Press. ZHANG, W. Y. (1999). English lexicology. Beijing: Foreign Language Teaching and Research Press. 